\title{
La revalorización de la salina de Valcargado (Utrera). Un proyecto basado en la gestión integral y la producción artesanal
}

\begin{abstract}
Valcargado es una de las pocas salinas de interior que continúan activas en Andalucía, después de que en los años cincuenta del pasado siglo la mayoría se vieran obligadas a cesar su actividad. Sin embargo, con sus instalaciones gravemente deterioradas, y en una fase de degradación patrimonial, se encontraba en peligro de desaparición hasta que en 2015 la situación cambia. A partir de julio de ese año la Asociación Andaluza de Artesanos de la Sal, con amplia experiencia en actuaciones de revalorización y gestión de salinas, formaliza junto con la propietaria de la salina un proyecto integral de recuperación.
\end{abstract}

Daniel Martínez Castizo | historiador y antropólogo

URL de la contribución <www.iaph.es/revistaph/index.php/revistaph/article/view/3949>

En la década de los cincuenta del pasado siglo, momento en el que el sector salinero se enfrentó a un obligado proceso de modernización de sus instalaciones y métodos de producción para abastecer a una industria que demandaba mayor cantidad a menor precio, la inmensa mayoría de las salinas de interior de Andalucía se vieron obligadas a cesar su actividad En ese contexto de fuerte competencia de capital, precio y alto volumen productivo, las pequeñas salinas de interior no fueron capaces de mantener su actividad y terminaron por cerrar.

En Utrera la salina se mantuvo activa gracias a un proceso de semi-industrialización y reorientación de la actividad salinera, pasando a producir en exclusiva una salmuera cuya calidad, cantidad y precio sí podía competir en el mercado.

Esta intervención condujo a la transformación y deterioro de bienes como las piletas y calentadores, cuyas estructuras y fondos empedrados desaparecieron. Además, el cambio en sus estructuras y en la concentración de sus aguas eliminó la fauna y flora características en las diferentes piscinas. El propio cortijo también sufrió un proceso de remodelación para dar cobijo a la maquinaria y taller, quedando el antiguo alfolí como almacén misceláneo de útiles o materiales de obra y mantenimiento. Así mismo, las antiguas instalaciones, cuyo último testimonio es el pozo romano, fueron simplemente deteriorándose por el abandono.

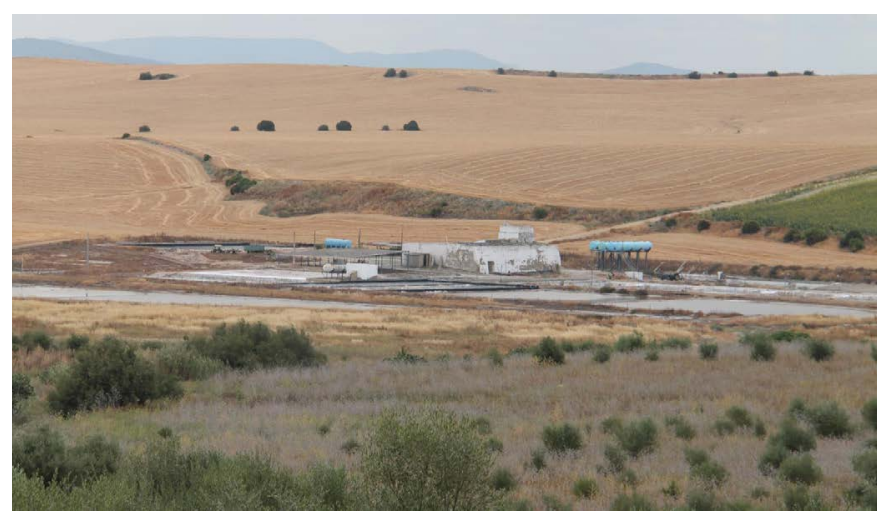

Salina de Valcargado | foto Andasal, 2017

De esta forma, el rico patrimonio cultural que durante siglos había acumulado Valcargado de la mano de los diferentes pueblos que hicieron uso de sus aguas para sacar el oro blanco de la campiña sevillana (romano, musulmán, visigodo y castellano), se encontraba en un estado de fuerte peligro de desaparición.

Afortunadamente esta situación de degradación patrimonial y monocultivo salinero comienza a cambiar en julio de 2015, cuando la Asociación Andaluza de Artesanos de la Sal (ANDASAL), que ya posee experiencia en actuaciones de revalorización y gestión de salinas, formaliza junto a la propietaria de la salina, Salinas de Valcargado S.L., un proyecto de gestión integral de patrimonio acompañado de la recuperación de la producción artesanal. Una propuesta que sigue los pasos del fenó- 
meno de puesta en valor ya andados en Europa durante las últimas décadas.

El proyecto consiste en la recuperación de la sal artesanal y la diversificación de su producción, ampliando la misma con una oferta de turismo y ocio (baños de sal, visitas, talleres, jornadas). Dada la envergadura de una propuesta de este tipo, la cual necesita de la participación de agentes públicos y la sociedad civil para la consecución de un Plan Director que lo haga viable, desde Andasal y Salinas de Valcargado S.L. han trazado una hoja de ruta estructurada en dos fases: una primera de mantenimiento de la actividad de la salina compaginada con la difusión, conocimiento y suma de aliados; y la segunda consistente en el planteamiento, redacción y ejecución del mencionado Plan.

En estos dos últimos años, Andasal y Salinas de Valcargado S.L. han llevado a cabo con éxito el desarrollo de la primera fase. En ella, el principal objetivo se centró en el acercamiento de Valcargado a Utrera y sus gentes, bien organizando encuentros como la charla-coIoquio Utrera, Tierra Blanca de Sal y Salero, o mediante visitas a sus instalaciones en las que se puede ver cómo se ha recuperado la producción artesanal de sal mediante técnicas tradicionales.

La producción de sal es uno de los grandes cambios operados en Valcargado, pues ha supuesto la paulatina restauración de las viejas piletas y calentadores, la vuelta a las tradicionales formas de cosechar sal, y por tanto, la recuperación de la esencia blanca de Valcargado. Pero además, el entorno de la salina está siendo repoblado con salicornias, una especie halófila que sirve de alimento para los pequeños mamíferos y también como suculento aditivo para nuestros platos. Recuperar el patrimonio cultural y natural de la salina a través de estos pequeños gestos está cambiando poco a poco su aspecto.

De esta forma, los primeros productos de Valcargado también están siendo conocidos en ferias y eventos gastronómicos y turísticos (cocinas de las Escuelas de Hostelería de la Fundación Cruzcampo, del I.E.S. Heliópolis de Sevilla, en el Atenea de Mairena del

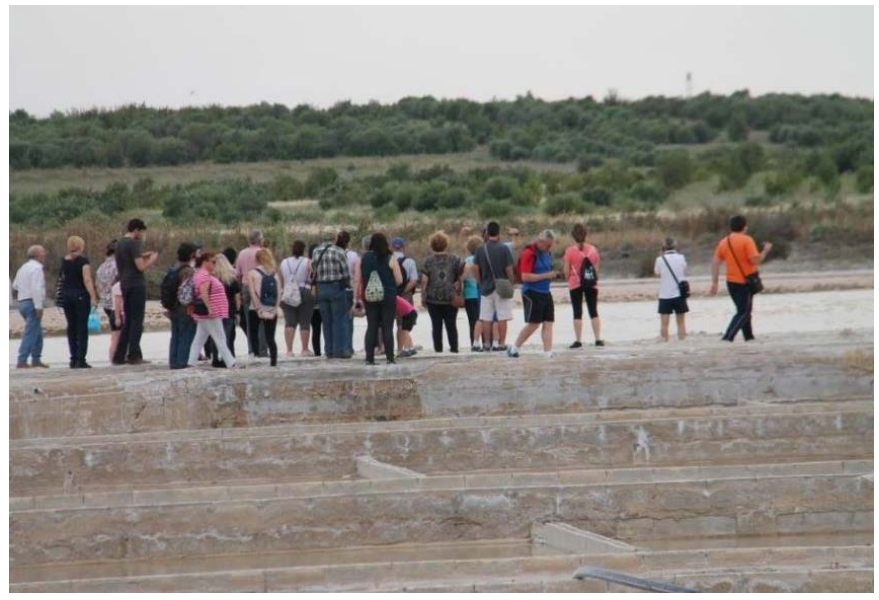

Visitas organizadas a la salina | foto Salinas de Valcargado S.L., 2017

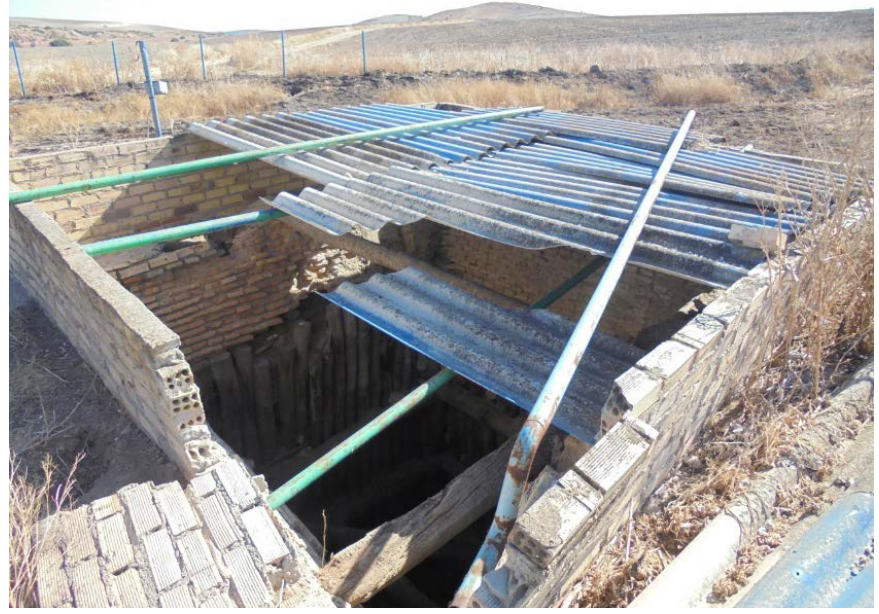

Pozo romano | foto Daniel Martínez, 2016

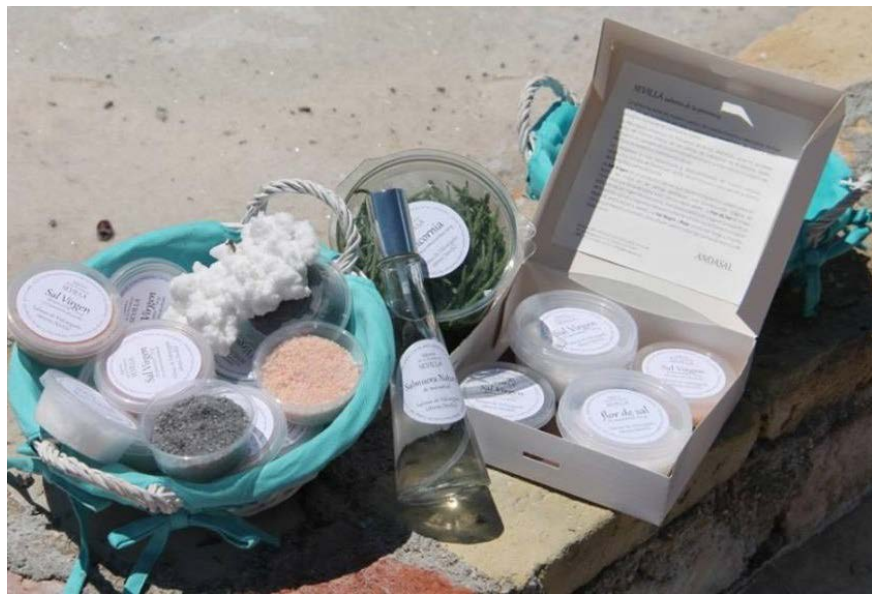

Productos de Valcargado | foto Salinas de Valcargado S.L., 2017 
Aljarafe, los Alminares en Arcos de La Frontera y la Escuela de Hostelería de Córdoba o Fitur). También cuenta con la aparición en diferentes medios de comunicación y programas de difusión ("Andalucía Directo", "Aquí La Tierra", "Tierra y Mar"), así como artículos en la prensa local y regional.

A toda esta labor debemos sumar el encuentro puntual con aliados del mundo académico e investigador en jornadas y eventos (Universidad de Huelva, Instituto del Patrimonio y los Paisajes de la Sal -IPAISAL- e IAPH), así como de organismos e instituciones públicas (Diputación de Sevilla, Ayuntamiento de Utrera y Prodetur), que han mostrado interés por el proyecto.
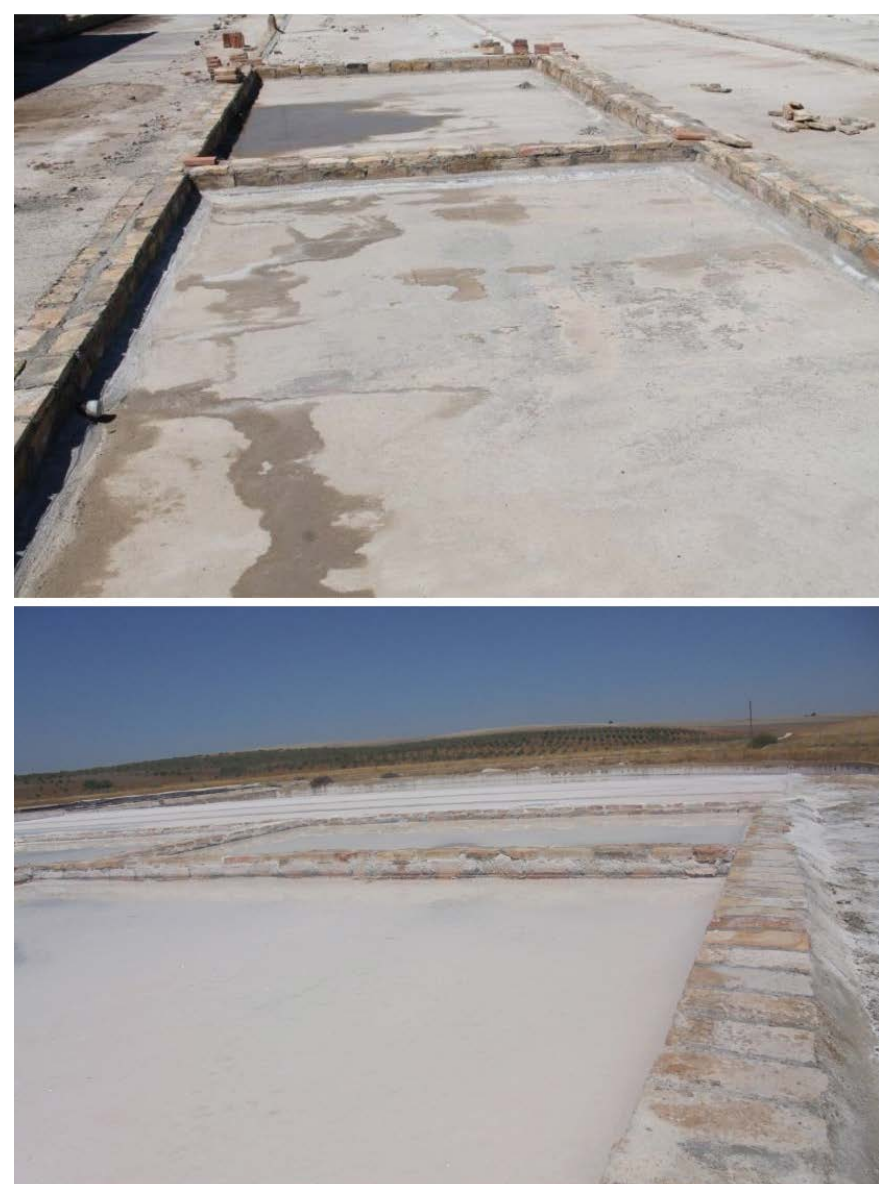

Comparativa piletas. En la imagen superior se puede ver el estado de las piletas antes de la intervención para la recuperación de la producción artesanal en 2015. Abajo las mismas piletas restauradas y con producción durante la campaña de 2016 | fotos Andasal, 2016
Con este camino recorrido, Andasal y Salinas de Valcargado S.L. esperan confirmar a lo largo de 2018 la puesta en marcha del Plan Director que consolide lo ya realizado y permita así dar un impulso definitivo en la mejora de las infraestructuras de acceso, instalaciones y servicios turísticos. El objetivo es hacer viable una gestión integral, sostenible y responsable del patrimonio salinero de Valcargado.

\section{BIBLIOGRAFÍA}

- BOJE PRIEGO, A. J. (2016) Salinas de Valcargado: Historia, patrimonio, naturaleza y economía. Hablemos de Utrera, $n .{ }^{\circ}$ 27, 2016, pp. 4-5

- FERNÁNDEZ-PALACIOS CARMONA J. M.; DELGADO MARZO, J. M. (2004) Salinas interiores de Andalucía. En PÉREZ, A. (coord.) Salinas de Andalucía. Sevilla: Junta de Andalucía, 2004, pp. 105-110

- HUESO KoRTEKAAS, K.; CARRASCo VAYÁ, J. F. (2008) Los paisajes ibéricos de la sal: las salinas de interior. Guadarrama: Asociación de Amigos de las Salinas de Interior, 2008, vol. I, 156 p.

- HUESO KORTEKAAS, K.; CARRASCO VAYÁ, J. F. (2006) Las salinas de interior, un patrimonio desconocido y amenazado. De re metallica, n. ${ }^{\circ}$ 6-7, 2006, pp. 23-28

- MARTínEZ CASTIZO, D. (2016) La puesta en valor de las salinas de interior en Andalucía. El proyecto de Valcargado (Utrera). Trabajo final de Máster inédito, 128 p.

- PÉREZ-huRTAdo de MENDOZA, A. (2004) El potencial de las salinas: hacia una conservación integral de las salinas andaluzas. En PÉREZ, A. (coord.) Salinas de Andalucía. Sevilla: Junta de Andalucía, 2004, pp. 286-294

- ROMÁN LóPEZ, E. (2014) Paisajes de la sal en Andalucía. Tesis doctoral inédita. Universidad Politécnica de Madrid, 2014

- SALINAS de Valcargado. Valcargado, balcón y puerta de Utrera. salinasdevalcargado.blogspot, 20 de junio de $2016<$ http:// salinasdevalcargado.blogspot.com.es/2016/06/valcargadobalcon-y-puerta-de-utrera.html> [Consulta: 26/6/2017]

- SALINAS de Valcargado (Sal y salmueras) Valcargado mina de Sal. salinasdevalcargado.blogspot <http:// salinasdevalcargado.blogspot.com.es/p/sal-y-salmueras.html> [Consulta: 26/6/2017] 